\title{
Morphology and Elemental Composition of Fine Particulate Matters PM10 by SEM-EDS
}

\author{
R. Ramirez-Leal ${ }^{1}$, M. Cruz-Campas ${ }^{1}$ and H. Estuardo-Moreno ${ }^{1}$ \\ 1. Sonora State University. Ley Federal del Trabajo s/n Col. Apolo, C.P. 83100; Hermosillo, Sonora, \\ Mexico. email: ramz1036@yahoo.com.mx
}

The chemical composition of the particles themselves, as well as the variety and amount of compounds sorbed on their surfaces, are other factors expectedly responsible for the health effects. In the ambient air, coarse particles are mostly derived from soil and sea salt. Fine and ultrafine particles are predominantly derived from combustion of fossil fuels and transformations of biogenic emissions.[2]

The use of electrons for the study of particles has had an enormous impact, allowing us to obtain an immense amount of information about the nature, origin, and chemical composition of a research's subject.[3]. The studies by EDS to PM10 showed the following elements:Al, $\mathrm{Ba}, \mathrm{Ca}, \mathrm{Cr}, \mathrm{Cu}, \mathrm{Fe}, \mathrm{K}, \mathrm{Mg}$, $\mathrm{Na}, \mathrm{S}, \mathrm{Si}$, Ti; and the predominant elements were Al (14.67 At\% ), Si ( $03.55 \mathrm{At} \%$ ), Ba ( $11.4 \mathrm{At} \%$ ) and Fe ( 09.15 At\%). (Fig. 2)

The aim of this work is identification and characterization (morphology and chemical composition) of particles present in samples of PM10 as part of an air quality study by SEM-EDS. Knowledge of the kinds of particles, especially those which are of wide spatial and chronological distribution, such as particles derived from industrial activities and from geological sources such as volcanoes and deserts, is necessary to build a specific assemble of each particle, being that the chemical composition of atmospheric aerosols varies according to its size, its geographic position and the season of the year.[1]

The City of Hermosillo is located between latitude $20^{\circ} 01^{\prime} 00$ "and $20^{\circ} 08^{\prime} 30^{\prime \prime}$ north latitude and between the meridian $110^{\circ} 54^{\prime} 30$ "and $111^{\circ} 01^{\prime} 00^{\prime \prime}$ west longitude at an altitude of $200 \mathrm{~m}$ above sea level; is the Sonora state's capital, located to the Center-West of the coastal plain, in northwestern Mexico.

The PM10 particles was collected by high-volume sampler, located in the northwest of the city, using a sampling flow of $1.3 \mathrm{~m} 3 / \mathrm{min}$. Sampling was carried for $24-\mathrm{h}$ one day a week. The filters used were quartz, with size of $8 \times 10$ inch that captured PM10 particles. Analysis of PM10 were performed using scanning electron microscopy (SEM) JEOL Model JSM-5800LV coupled with energy dispersive spectrometer (EDS) EDAX DX prime brand, for determination of morphology and elemental composition of airborne particles. Specimens were processed by separating the collected particles from the quartz filters by means of submersing a $2 \mathrm{~cm} 2$ section of each filter into isopropilic alcohol within a test tube for 5 minutes. Then, an aliquot of the suspension was placed over a sample holder, and is introduced into the chamber of SEM.

It is observed that the morphology of the particles is irregular, rough, smooth and with agglomerates.(Fig. 1)

The results obtained from the characterization of the particles captured showed that these particles are composed primarily of feldspar (Al, $\mathrm{Si}, \mathrm{Ca}$ or $\mathrm{Al}, \mathrm{Si}, \mathrm{K}$ ) and clay (Al, $\mathrm{Si}$ or $\mathrm{Al}, \mathrm{Si}, \mathrm{Fe}$ ), their origin is 
mainly crustal, but they can also come from erosion of building products and road dust. Barium, its occurrence can be explained partly as result of soil re-suspension processes, to contributions of road surface abrasion, road dust, brake and tire wear. "Given that there is relatively little knowledge on speciation and size of atmospheric particles, the elements found among the atmospheric particles caught on PM10 filters highlight the importance of individual characterization of atmospheric aerosol. This knowledge is valuable additional information about the possible actions and potential effects that air pollutants, of natural or anthropogenic origins, have within the studied area"

\section{References:}

[1] Ma. Cristina Castañón Bautista et al. 2015. International Journal of Applied Science and Technology. Vol. 5, No. 2

[2] Yunbo Zhai, Zongmin Fu and Lafang Wang. 2012. Environ Monit Assess 184:6693-6707

[3] R. Ramirez-Leal, Microsc. Microanal. 15 (Suppl. 2) (2009) 1300-1301.
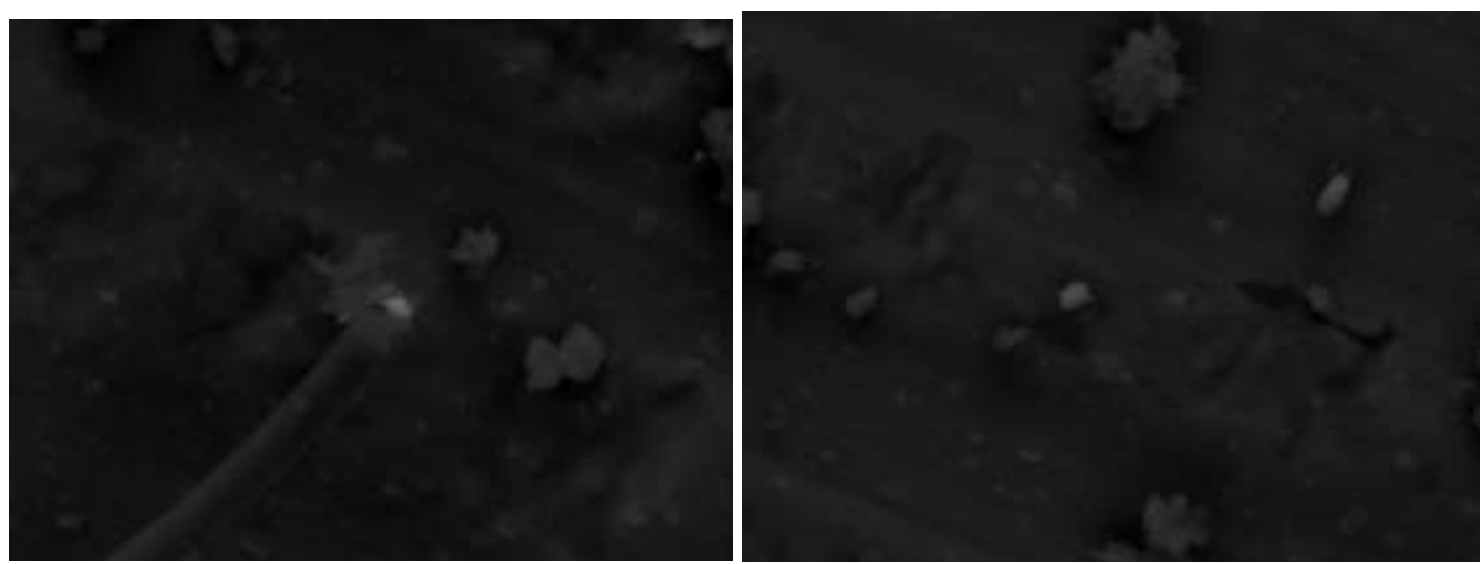

Figure 1. Micrograph of the sample in SEM-EDS. 5000x BEI and $15 \mathrm{kV}$

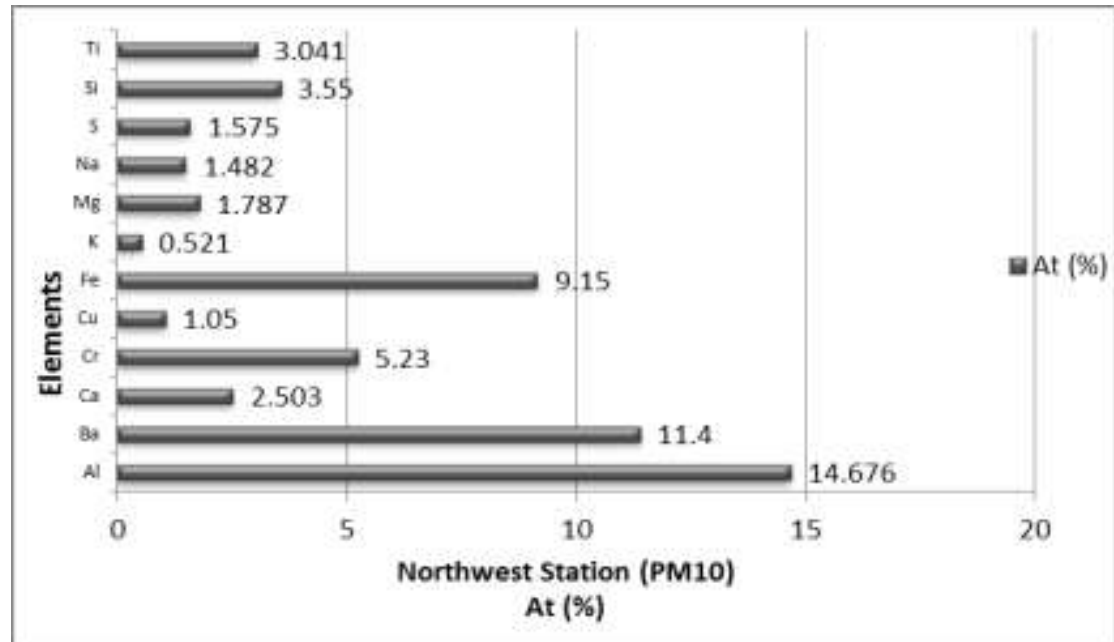

Figure 2. Majority of elemental constituents of PM10 samples in northwestt area (Averaged values of atomic percentage (At $\%)$ for all filter samples). 